\title{
Epidemiological Aspects of Dysphonia in Tertiary Care Hospital
}

\author{
A H M Delwar ${ }^{1}$, Kishore Halder ${ }^{2}$, Nurul Chowdhury ${ }^{3}$, and ABMT Hossain ${ }^{4}$ \\ ${ }^{1}$ Comilla Medical College \\ ${ }^{2}$ Abdul Malek Ukil Medical College \\ ${ }^{3}$ Chittagong Medical College \\ ${ }^{4}$ Universiti Malaysia Sabah School of Medicine
}

July 14,2020

\begin{abstract}
Objective: To find out the prevalence, etiology, risk factor, presentation and treatment option of the dysphonic people, facilitate the prevention of the risk factor of it. Study Design: Cohort retrospective study. Setting: Academic tertiary care medical center. Subjects and Methods: A total 1739 dysphonic patient's demographic data collected and analysed who attended in the department of Otolaryngology and Head-Neck Surgery, Comilla Medical College, and Comilla Medical Centre, Bangladesh. Results: Incidence of dysphonic patient was $1.16 \%$, and yearly prevalence $33.33 \%$. Out of 1739 , the male was 1006 (57.85\%), and the female was 733 (42.15\%), 50-59 years were highest presentation 488 (28.06\%). Among 1739, non-specific chronic laryngitis was 1015 (58.37\%), dysphonia without structural change (MTD) 417 (23.98\%), and malignancy 90 (5.17\%). Off them, smoker was 911 (52.39\%), voice abuser 469 (26.97\%), industrial worker was 477 (27.43\%), teacher 359 (20.64\%), singer 151 (8.68\%), and slum dweller was $528(30.36 \%)$. Presenting feature revealed hoarse voice, reduced loudness, and tiring to talk above $90 \%$. All patients assessed by rigid Hopkin's telescope. Non-neoplastic benign and suspected malignant lesion was 1503 (86.43), neoplastic benign and malignancy was 236 (13.57\%), conservatively treated 1512 (86.43\%), and surgically 227 (13.6\%) treated by micro-laryngeal surgery. Conclusion: Dysphonia effect more than $33 \%$ of people at some point of life. It definitely influences the quality of life and losing the patient health and wealth. Early and effective treatment decreases the further loss.
\end{abstract}

\section{Hosted file}

Epidemiological_Aspects_of_Dysphonia_in.docx available at https://authorea.com/users/342802/ articles/469625-epidemiological-aspects-of-dysphonia-in-tertiary-care-hospital

\section{Hosted file}

Tabies and figures epidemiological aspecs of dysphonia.docx available at https://authorea. com/users/342802/articles/469625-epidemiological-aspects-of-dysphonia-in-tertiary-carehospital 